\title{
Analysis of Conflict and Solution between Information Disclosure and Commercial Secret Protection in Listed Companies
}

\author{
Jinghua $\mathrm{Ji}^{1}$, Dan Chang ${ }^{2}$ \\ ${ }^{1,2}$ College of Business Management, Changchun University of Technology, Changchun Jilin,130012, \\ China
}

Keywords: Listed company, Information disclosure, Commercial secret protection, Conflict, Solution.

\begin{abstract}
Considering the problem of information disclosure and commercial secret protection from the aspect of operation of modern market economy, essentially both have obvious conflict and contradiction no matter in theory or practice. From theory, what could reflect system's public law property is the three basic principles of fair, open and just information disclosure. However, this system is the core of Securities Act, with the final aim of fully maintaining investors' investment interests and meanwhile it needs to make sure the operation of stock market being more in order. However, commercial secret protection refers to fully protection to intracompany information with some economic value to make favorable economic and competition interests. Thus, its private law property is very obvious. The former is aimed at protecting investor interests while the latter protecting the company's own interests, where conflict inevitably exists. During practice process, in order to better protect investor interests, security supervisory authorities would ask listed companies to announce information to the greatest extent. However, once over announced, it would easily reveal business secret in company. In addition, if listed companies want to maintain self competitive advantages and get most interests all the time, there should not be willing to information disclosure, especially those information close to business secret. However, stock market is the information market in essence. Thus, if excessively attaching importance to business secret protection, it would have direct influence to information disclosure and bring serious injury to investor interests. Therefore, it is of great practical significance to further study the conflict and solution of information disclosure and commercial secret protection in listed companies.
\end{abstract}

\section{Specific manifestation of conflict between information disclosure and commercial secret protection in listed companies}

\section{Manifestation of conflict in legal ideas}

The information disclosure in listed companies belongs to securities legislation while the commercial secret protection system is different which mainly belongs to category against unfair competition law. It shows that value criterions and ideas in both are different. Main purpose of information disclosure in listed companies is to fully protect investor interests, guarantee market order and public interests. However, the main purpose of commercial secret protection is to maintain company itself competitive advantages ${ }^{[1]}$. Under the current historical background with information explosion, the key of enterprise competition lies in the amount of information. Thus, if enterprise has this scarce resource, it would provide powerful guarantee to its future development and subsistence. However, once the enterprise information or technical security is ignored, it would easily be defeated by peers. Therefore, there is obvious conflict in legislation of the above two systems. Specific manifestation is 
the information content that must announced due to business secret extension, especially the cross section of information with some values.

\section{Manifestation of range conflict between information disclosure and commercial secret protection}

Securities Act has definitely stipulated that once it is possible to affect prices buying and selling of stocks in listed companies but investors can never know, it needs listed companies to report relevant condition securities regulatory authority and securities exchange of the State Council, submit temporary report and meanwhile announce and explain the essence of this matter in detail ${ }^{[2]}$. Important events mentioned above cover wide-range content, embodying guideline for management in the company appearing larger changes to actual range; significant investment behavior or property purchasing decision in listed companies; signing contracts bringing some influences to itself property, rights and interests, incur debts or business performance; condition with such big change of operation or chairman or more than $1 / 3$ directors; holding more than $5 \%$ shareholders whose shares changing a lot, etc. However, it is against unfair competition law whose business secret covers design procedure, specific formula and making technology of products. In addition, it also comes down to administrative skills or clients' particular list, base number of a tender, real information of supply of goods, production and sales strategies, etc. It shows that there is obvious conflict in information disclosure and commercial secret protection in listed companies, specifically reflecting that once production and sales strategies change obviously, it needs to disclose information according to Securities Act. However, production and sales strategies also belong to business secret, which need comprehensive protection. Thus, their conflict becomes very obvious. What's more, if the listed company wants to sign quite important contract, even though it may affect its own business performance, property, rights and interests or liabilities, it needs information disclosure according to Securities Act. However, since the signed contract has some importance, it would definitely involve important information of clients, supply of goods, etc. The client list and information of supply of goods belong to commercial secret protection. Thus, there is conflict again.

\section{Source of existence of information disclosure and commercial secret protection}

Firstly, trade secret right in listed company is limited by shareholders' right to know. From the aspect of legal rights of listed company and investor, it is essentially the conflict between trade secret right and shareholders' information right. If listed company chooses financing, it would issue shares. When investor buys these listed shares, they has the stockholder's rights immediately. And the stockholder's rights include request rights of dividend distribution and residual property distribution, voting right, right to know, etc. At the same time, their right to know is the important premise of other rights. However, as to commercial secret protection, according to specific theoretical analysis of property right, since business secret belongs to intangible property with some value and use value, it plays significant role in enterprise competition. However, if choosing to seek financing by listing on the stock market, company's own rights would be limited by investors' right to know. It shows that the conflict between information disclosure and commercial secret protection in listed companies is the conflict of interests in essence.

Secondly, it refers to the choice of proportion analysis between cost and profit in listed companies. From the cost analysis of economics, information disclosure in listed companies is always decided after analyzing proportion between cost and profit ${ }^{[3]}$. By model analysis, since the cost of information disclosure of listed companies is made up by two parts, one is the cost relevant to information disclosure as R1, and the other is indirect cost as R2. In addition, stock yield in listed companies is the economic cost by economic cost, as V1. Thus the final profit $S 1=V 1-R 1-R 2$.

From the aspect of commercial secret protection, cast to commercial secret protection could also be divided into two parts. The first is the direct cost by adopting cryptosecurity as R3. The second is indirect cost which refers to the profit that might be given up due to commercial secret protection as $\mathrm{R} 4$. And the profit could be V2. Thus, profit of commercial secret protection is $S 2=V 2-R 3-R 4$. 
By the above model analysis, it finds that V1 equals R4, V2 to R2, thus the final profit could also be $S 1+S 2=-R 1-R 3$. However, since $\mathrm{R} 1$ and $\mathrm{R} 3$ are always greater than zero, profit is minus, which could further mean that company hoping to realize common profit of commercial secret protection and floatation of shares is impossible and there must be severe conflicts.

\section{Overall coordination of information disclosure and commercial secret protection in listed companies}

\section{To divide information bound with content and space as standard}

Firstly, to divide information according to contents. Conflict between information disclosure and commercial secret protection in listed companies is obviously in contents. Thus it needs to be adjusted. The most important is to define and divide the disclosed information range and concept of business secret. According to the Provisional Regulations of Stock Issuance and Transaction Management and Contents and Format Standard of Information Disclosure in Companies with Public Floatation, if condition is identical, listed companies have the right to not issue information related to business secrets ${ }^{[4]}$. As to those information contents that must be disclosed, it should firstly confirm them, make significant standard and then analyze whether the information contents are related with business secrets. Finally it should ensure it has rules to follow to disclose the information or not. As to the business secrets, as long as the information has some economic value to obliges or has adopted corresponding safeguard procedures, it belongs to business secret. Thus, in order to effectively release conflict between the two, it must divide the information contents. And the significant standard should affect the investment decision of investors. Uppermost reason is that once it affects the investment decision, it would affect corresponding share price.

Secondly, to divide information according to time. Great information contents must be disclosed. But it has the time standard, because some matter of the least concern may turn into matter of the utmost concern by situation change. At the same time, many matters that are primarily decided not to disclose may turn into matter of the utmost concern. Thus, the time is obvious in flexibility and variability, which should meet an emergency by physical truth.

\section{To effectively complete commercial secret protection mechanism in listed companies}

Commercial secret protection mechanism in listed companies mainly includes exemption mechanism and punishment mechanism of business secret. The exemption mechanism refers that even its business secret might bring some influence to investors' investment and decision but not very great, company could apply for exemption of disclosure to securities exchange. The actual operation of this mechanism is of great significance to the overall protection to listed company information and meanwhile could make sure the stable development of securities market. According to the relevant stipulations of CSRC, if the disclosed information contents is very important business secret with high value, it could be appropriately simplified during practical disclosure. By above analysis, listed companies could flexibly use this stipulation and guarantee social groups could know this concept of business secret probably. In addition, it could also guarantee listed companies possess independent operation right in business secret to avoid getting by other peers. At last, listed companies should adopt fully protection measures before disclosing business secrets.

\section{To suitably improve judicial remedy procedure}

\section{To make civil confirmation system of business secret based on information disclosure exemption}

Firstly, to clear and definite the application right of exemption of disclosure. If the information of listed companies has evident to prove it belonging to business secret, listed companies could immediately propose corresponding exemption of disclosure to securities regulation institution and submit collected evidences. When institution receiving the application, it needs to implement fully 
inspection and make final decision. However, the practical inspection time can not surpass 3 days. Only then could guarantee timeliness of the information ${ }^{[5]}$.

Secondly, if the securities regulation institution votes down application, meaning the information is proved not belonging to business secret and must be disclosed, but listed companies are not satisfied with the results, then they could ask for civil judgment from the local people's court. The purpose of this judgment is to judge the nature of business secret of information. If it is finally judged to be business secret, it could exempt disclosure. Once it is judged not to be business secret, listed companies should disclose information immediately and undertake the responsibility of bringing economic losses to investors due to time delay. In addition, it should reasonably build independent judgment degree and time limit to this judgment system to better realize overall coordination between information disclosure and commercial secret protection in listed companies.

\section{To increase law enforcement efforts}

The current securities legislation has not perfect legal liability stipulations in information disclosure in listed companies, not enough punishment to unlawful acts and low cost of violation of laws, which make listed companies easily risk danger in desperation for on their own account. Thus, it should inspect the illegal disclosure acts to examination and supervision process in CSRC based on corresponding rights.

\section{Conclusion}

To sum up, according to the above analysis and study, it could find that there is essential difference between information disclosure and commercial secret protection in listed companies but certain inherent uniformity. It must ask legislator to think deeply from cost-effectiveness and guarantee the interests of listed companies and investors. Thus, it could not only promote technological level of governmental supervision department but also realize effective coordination of the conflict.

\section{References}

[1] Chen Fei, Game Playing Study of Information Disclosure and Commercial Secret Protection in Listed Companies, administrative enterprise property and financial affairs, 2012(12): 74-75.

[2] Wu Yannan, Conflict and Coordination of Information Disclosure and Commercial Secret Protection in Listed Companies, Southwest University of Political Science and Law, 2013.

[3] He Zhenghong, Information Disclosure and Commercial Secret Protection in Listed Companies, development, 2010(4): 76-77.

[4] Bian Tao, Relation of Information Disclosure and Commercial Secret Protection in Listed Companies, business conditions, 2012(52): 61.

[5] Deng Qing, On Information Compulsory Disclosure and Commercial Secret Protection in Listed Companies in China, new finance and economics (Theoretical edition), 2013(10): 114-114. 